\title{
INVESTIGATING THE RELATIONSHIP BETWEEN RAINFALL INTENSITY, CATCHMENT VEGETATION AND DEBRIS MOBILITY
}

\author{
* Rick Jaeger and Terry Lucke \\ Stormwater Research Group, University of the Sunshine Coast, Australia \\ *Corresponding Author, Received: 10 July 2016, Revised: 15 July 2016, Accepted: 07 Oct. 2016
}

\begin{abstract}
Urbanisation creates the need for engineered hydraulic structures in catchments, floodplains and watercourses. These include piped and open-channel drainage networks, flood control systems and waterway crossings such as culverts and bridges. During larger storm events, debris and other material located higher in the catchment can be mobilised and transported towards these hydraulic structures creating the potential for blockages. This debris is often trapped by the hydraulic structures, causing partial or full blockage which can reduce the flow capacity of the structure. This may cause upstream flooding during high intensity rainfall events. This study investigated the debris transport behaviour in a natural channel. A model of an existing catchment and culvert system in Australia was build based on Froude similitude scaling. Different sized twigs were used to replicate natural debris of various sizes. The experimental results demonstrated that the mobility of debris during rainfall events was dependent on a range of factors including stream depth and width, the size and availability of debris, and on the condition of the riparian vegetation within the catchment. This could have significant implications for culvert design and maintenance procedures.
\end{abstract}

Keywords: Culvert Design, Catchment Vegetation, Flooding, Debris Transport, Stormwater.

\section{INTRODUCTION}

The increase in impervious surface areas accompanying urban development has increased both the total volume of stormwater runoff, and the speed at which concentrated stormwater flows reach downstream receiving waters $[1,2]$. Consequently, the management of stormwater in urban areas has become a significant issue for those responsible for planning and construction of new developments, and the maintenance of existing stormwater infrastructure [3].

The installation of culverts is a traditional approach to managing stormwater flows caused by the runoff from storm events and they have been shown to be a reliable method of managing flood risk in urban areas [4]. Culverts are generally placed within the channel of both natural and artificial waterways and this can often result in flow constrictions within the channel. These constrictions can be the limiting factor during high intensity rainfall events which might lead to flooding. Culverts are also prone to blockage by a range of different flow conditions which can further increase the risk of flooding. Culvert blockages can also result in higher flood levels, changes to stream flow patterns, changes to stream bed and bank erosion, changes in sediment deposition patterns in channels, as well as physical damage to the culvert and surrounding structure caused by debris $[5,6]$.

Several main factors have been identified that influence the blockage of culverts by debris. These include:

- Debris (variety, size, amount, type)

- Debris availability (permanent, infrequent)

- Mobility (capability of debris to be moved)

- Interactions of debris with the structure itself.

The type, size and amount of debris, and its influence on blockage have been classified previously in a report by Engineers Australia [7]. However, many of the assumptions underpinning the classifications in this report remain untested. There is still much uncertainty regarding debris movement in natural channels where a variety of factors can influence the debris mobility. To further investigate these uncertainties and to address this knowledge gap, a series of laboratory experiments was undertaken in this study. The hydraulic performance of an existing culvert and channel in Nambour, Australia, was modelled in the laboratory in order to improve understanding of debris movement within the channel, as well as the main factors influencing this movement. 


\section{PREVIOUS RESEARCH}

A scaled laboratory model was used to investigate the debris mobility of the existing Nambour culvert. Froude similitude scaling was used to achieve realistic flows in the model [5]. Froude similitude scaling is one of the most traditional methods used to scale laboratory experiments [5, 8-10]. The Froude number is a dimensionless ratio between the flow velocity and gravitational forces together with the characteristic length [11]. This method focuses on sub- and supercritical flow conditions, as well as on the flow velocities within the stream, rather than relying on turbulence differences described by the Reynolds number [9]. While there are limitations to this method, it has been found to be an acceptable method of analysing open-channel flows with low Reynold numbers in the area of interest [12].

Blockage of hydraulic structures remain unpredictable in most cases as the process is based on a number of highly-variable factors. The first unknown factor is blockage of the culvert itself. While much research has been done in this area, a precise tool to predict blockage has yet to be developed [13]. The likelihood of a blockage is highly dependent on the dimension and geometry of the culvert, as well as the debris shape, size and availability. Whereas culvert geometry can be determined precisely, the debris availability is highly dependent on the upstream riparian fauna and on its mobility [7, 14]. Riparian vegetation is not as easy to assess as culvert properties and its composition is also likely to change over time. However, it is possible to obtain a general assessment of upstream conditions through local inspections or low-level aerial photography [15]. Knowledge regarding the condition of the upstream vegetation is an important factor in predicting the shape and size of the debris. However, an element of uncertainty still remains [15].

Debris availability in Australia is generally classified into high, medium and low availabilities [6]. A high availability of debris can be found in dense forests with thick vegetation, as well as in urban areas where a variety of loose materials are available. Areas with an irregular distribution of rainfall with high rainfall intensities are also known for their high debris availability [6]. Low debris availability areas on the other hand are characterized by rural lands, uniform annual rainfall and stable banks with flat or moderate slopes. The medium debris availability covers everything in between the first two categories [7].

If debris is available, it is often mobilized by wind or by flooding. Branches, and even whole trees, can break off or fall down during strong winds and these can end up in the channel and be washed downstream. During flooding, more area is covered by water and debris deposited on higher ground might be mobilized by the expanded channel flow [16]. Once the debris is entrained in a stream, it generally travels a random distance depending on the length and size of the debris, the width and depth of the streambed, flow velocities and the number of obstacles, as well as the distance between them [10, 17].

A number of previous studies have investigated the entrainment and transportability of debris. van Sickle and Gregory [18] developed a general probabilistic model for the provision of large woody debris (LWD) from falling trees. Their model could predict LWD's volume and orientation in the stream fairly well, but lacked the ability to accurately predict the length of the LWD. This was due to a missing function to allow for the breakage of falling trees [18].

In an experiment by Braudrick and Grant [19], the transport and deposition of LWD was investigated using a flume model. They concluded that there is a relationship between the LWD's length, the average channel width and the maximum radius of the channel's curvature. They found that in cases where a large portion of the channel area was less than the buoyant depth of the debris, once they were entrained within the flow, the smaller LWDs would not travel as far along the channel as larger LWDs because of their lack of momentum [19].

Whether or not a LWD is entrained by a stream depends on two main factors: The LWD's orientation and the existence of root balls. LWDs with root balls achieve more stable flow compared to the ones without root balls [8]. The root ball creates an unsymmetrical LWD shape and this tends to result in a bias towards one flow orientation which is more stable than others [8]. At the same time, root balls often result in a greater overall draft, which could result in the LWD getting stuck in shallow depth.

Bocchiola et al. [10, 20] performed a series of laboratory flume experiments to collate information on the jamming behaviour of LWDs. They found that the travelling distance of a LWD depends on its 
length, the spacing between any obstacles in the flow, and the force exerted by the current [10]. Their results demonstrated that the likelihood of trapping increases with the LWD's length and decreases with an increasing Froude number, as well as with a greater distance between one obstacle to the next [10].

In cases where the debris reaches the culvert inlet two possibilities may occur: 1) the debris flows through the culvert without causing a reduction in the hydraulic performance; or 2) it gets stuck at the culvert inlet, which can reduce the flow capacity of the culvert and cause upstream flooding. The likelihood for the first case was investigated in experiments as well as in a transient 1D flow model which was able to reproduce the experimental measurements [21].

A review of previous literature has shown that the factors affecting debris mobility in channels and culvert blockage by debris are not well understood. This paper attempts to address this knowledge gap by investigating the mobility behaviour of debris in natural channels both with and without riparian vegetation.

\section{APPROACH}

To increase the knowledge on LWD transport behaviour during high intensity rainfall events this study investigated debris movability of an existing culvert by undertaking a modelling study on a scaled laboratory testing rig. The first step involved undertaking a detailed topographic survey of an existing field site located in Nambour, Queensland, Australia (Figure 1). Contour levels of the 15 ha site were established, mapped, and then overlayed into AutoCAD to provide a detailed 3D digital elevation model (DEM). The DEM was then used to construct a 1:25 scale laboratory model of the site to be used in the study.

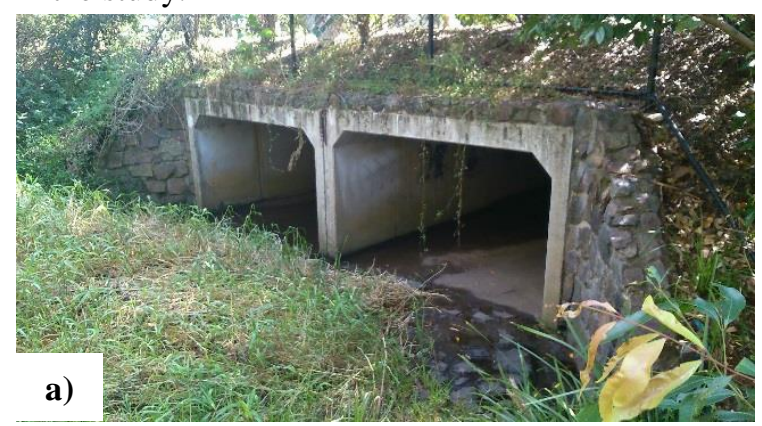

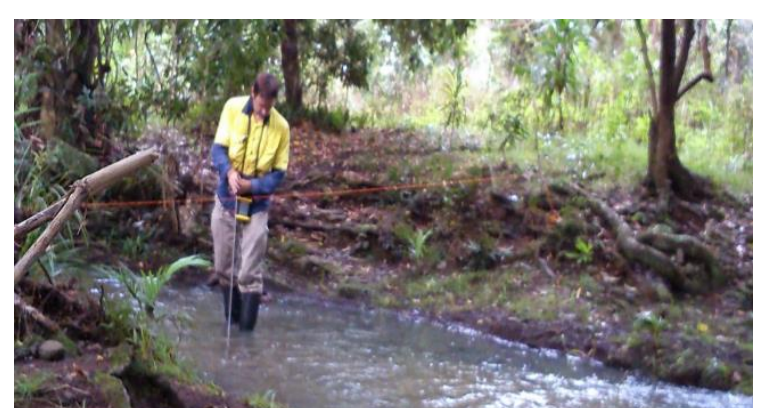

b)

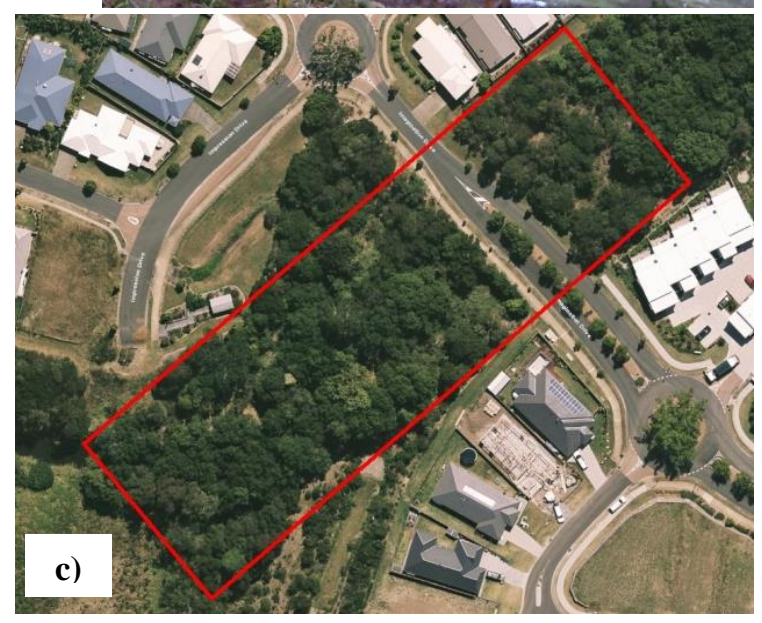

Figure 1: Study site; a) Existing culvert; b) Upstream catchment characteristics; c) Study area

To scale the model and the flowrates, a Froude similitude approach was chosen. To describe high intensity rain events, the Average Recurrence Interval (ARI) was used, which gives a likelihood on how often certain rainfall events happen statistically [22]. The estimated flowrates for ARI events from 2 to 100 years were modelled with a hydrological analysis using the Watershed Bounded Network Model (WBNM) [23]. The flowrates used in the study were calculated using a Froude similitude scaling approach using Equation 1 [24].

$$
\frac{\mathrm{Q}_{\mathrm{m}}}{\mathrm{Q}}=L^{5 / 2}=\left(\frac{1}{25}\right)^{5 / 2}
$$

where:

$\mathrm{Q}_{\mathrm{m}}=$ Model Discharge $\left(\mathrm{m}^{3} / \mathrm{s}\right)$

$\mathrm{Q}=$ Real Discharge $\left(\mathrm{m}^{3} / \mathrm{s}\right)$

$\mathrm{L}=$ Linear Scale Ratio

The flowrates calculated using Equation 1 and tested in the study are listed in Table 1. 
Table 1: ARI Flowrates using Froude similitude

\begin{tabular}{ccc}
\hline $\begin{array}{c}\text { ARI } \\
\text { (Years })\end{array}$ & $\begin{array}{c}\text { Real Flow } \\
\left(\mathrm{m}^{3} / \mathrm{s}\right)\end{array}$ & $\begin{array}{c}\text { Model Flow } \\
(\mathrm{L} / \mathrm{s})\end{array}$ \\
\hline 2 & 14.8 & 4.74 \\
5 & 22.0 & 7.04 \\
10 & 26.8 & 8.56 \\
20 & 33.0 & 10.5 \\
50 & 37.7 & 12.1 \\
$100 *$ & $43.8 *$ & $14.0 *$ \\
\hline *100 year flows were observed to overtop the model \\
culvert are not included in the paper results
\end{tabular}

To model the site topography, a custom-made culvert test rig (Figure 2), comprised of structural steel frame supporting a sealed plywood surface was constructed for the study. The test rig has a capacity to create slopes of up to $15 \%$ and had a surface area of approximately $20 \mathrm{~m}^{2}$. A submersible pump placed in an underground concrete tank (maximum flow rate of $35 \mathrm{~L} / \mathrm{s}$ ) was used to supply any pre-defined storm event for testing.

The site survey DEM was used to produce a 1:25 scaled model test rig. Overlain by a non-woven geotextile and topped with washed river sand, a precisely contoured layer of washed gravel (up to $25 \mathrm{~mm}$ diameter) was placed on the culvert test rig to produce the scale model of the upstream characteristics of the field study culvert (Figure 2).

Twigs and other natural materials were placed along the sides of the channel model up to $2 \mathrm{~m}$ upstream (50 $\mathrm{m}$ in real stream) to replicate existing vegetation. No vegetation was replicated along the channel sides between $2 \mathrm{~m}$ and $4 \mathrm{~m}$ (Figure 2) in order to evaluate the effects of having no vegetation.

Purpose built, transparent scale models of the existing Nambour culverts were positioned twothirds of the way along the test rig to simulate (as far as practicable) a scale model of the existing site conditions (Figure 2).

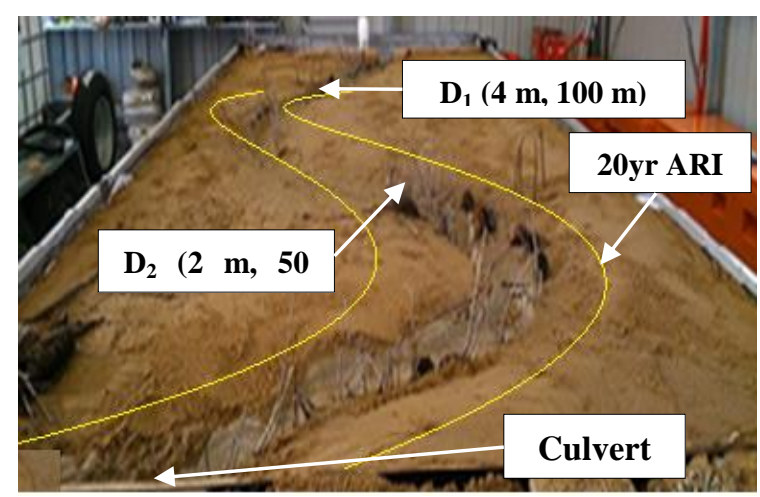

Figure 2: Laboratory Model Used in Study (looking upstream); 20yr ARI flowlines highlighted

The existing Nambour culverts were designed to withstand a $1 \%$ average exceedance probability (AEP) flood event [22] and the range of flows in Table 1, calculated by Froude similitude were tested in the study. It was found that the model overtopped at the 100 years ARI rainfall intensity of $43.8 \mathrm{~m}^{3} / \mathrm{s}$ $(14.0 \mathrm{~L} / \mathrm{s}$ on model) so these results were not included in the study findings.

\section{DEBRIS - TRANSPORT}

For the debris mobility testing, scaled twigs were used to model LWD movement within the stream. Smaller diameter, shorter twigs were used to model smaller LWDs and larger diameter, longer twigs were used to model large LWDs (Table 2).

Table 2: Debris dimensions and scaling at 1:25

\begin{tabular}{clccc}
\hline \multicolumn{2}{c}{ Debris } & S & M & L \\
\hline \multirow{2}{*}{ Length } & Real $(\mathrm{m})$ & $\mathrm{L}<1.5$ & $1.5>\mathrm{L}<2.9$ & $3>\mathrm{L}<4.5$ \\
& Real $(\mathrm{mm})$ & $\mathrm{L}<60$ & $60>\mathrm{L}<116$ & $120>\mathrm{L}<180$ \\
Diameter & Real $(\mathrm{m})$ & $50-100$ & $125-150$ & $175-200$ \\
& Real $(\mathrm{mm})$ & $2-4$ & $5-6$ & $7-8$ \\
\hline \hline Channel & Real & \multicolumn{3}{c}{$3 \mathrm{~m}$} \\
width & Model & $120 \mathrm{~mm}$ \\
\hline
\end{tabular}

To compare the mobility between different release areas and the influence of the vegetation, two different LWD drop-in locations were chosen $\left(\mathrm{D}_{1}\right.$ and $\left.\mathrm{D}_{2}\right) \cdot \mathrm{D}_{1}$ was approximately $4 \mathrm{~m}$ upstream (100 m in real channel) of the model culvert inlet and was directly within the first curve of the stream. $\mathrm{D}_{2}$ was approximately $2 \mathrm{~m}$ upstream (50 $\mathrm{m}$ in real channel) of the model culvert inlet and was in the second curve. Vegetation was installed along the sides of the model channel up to location $\mathrm{D}_{2}$ to replicate the real vegetation (Figures $3 \& 4$ ).

A set amount of various sized debris was dropped at these locations and then monitored. Each flowrate was tested with all three different debris sizes. After stable flow conditions were established for each ARI, 10 twigs of each debris size were released at points $D_{1}$ and $D_{2}$. After 10 minutes, the flow was switched off and the number of twigs stuck in the stream bed were counted as well as the number that went through the culvert. Each test was repeated five times. 


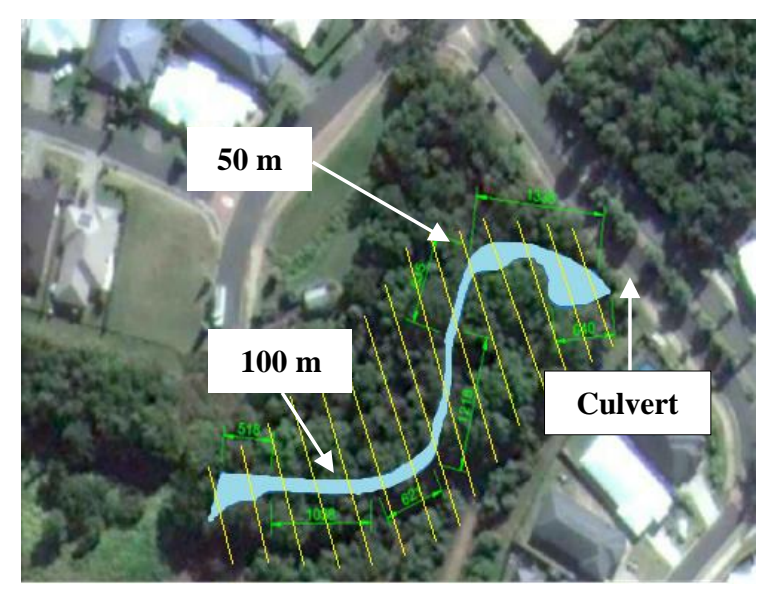

Figure 3: Real stream debris release distances (scaled in model); streambed and 50yr ARI flow area highlighted (hatched yellow)

The vegetation installed along the sides of the second curve would become submerged incrementally as higher flowrates were tested. As vegetation was only modelled in the curve (Section B-B in Figure 4) and stream closer to the culvert, its influence on the debris trapping could be analysed and compared to the debris mobility upstream in Section A-A (Figure 4) as both curves had similar shapes and profiles. Only the directions of the curves were different.

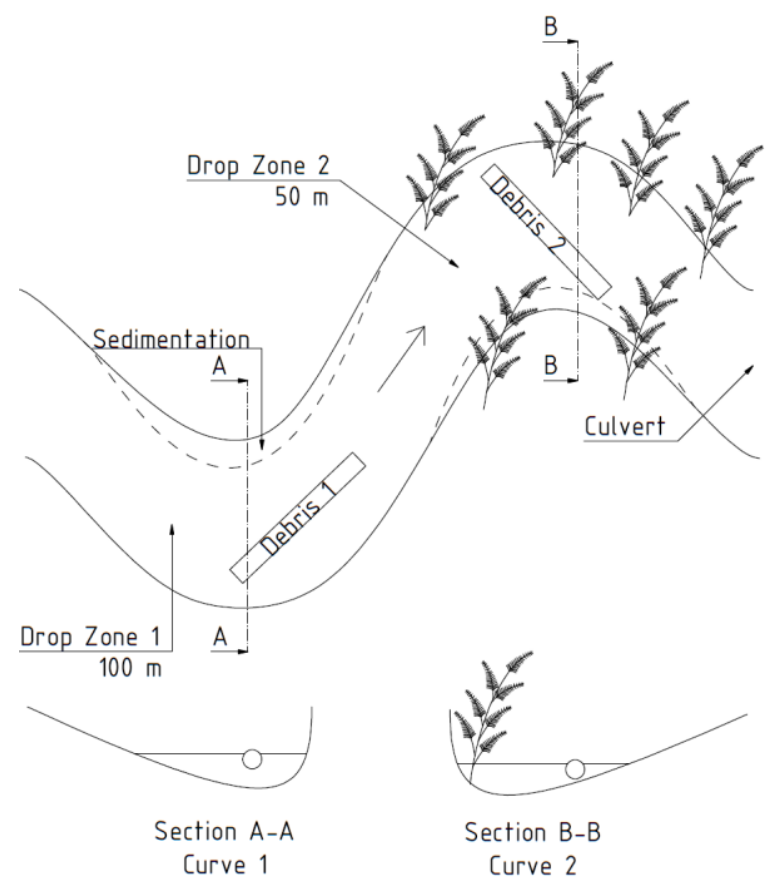

Figure 4: Debris flow in the channel (not scaled)

\section{DEBRIS - TRANSPORT - PRELIMINARY RESULTS}

The debris mobility testing identified different trends depending on the distance the debris travelled. When the twigs were deposited into the stream at location $\mathrm{D}_{1}(100 \mathrm{~m})$, the maximum amount of debris reaching the culvert was found to occur during the simulated 10 year or 20 year ARI flows for all three debris types (Fig. 5). The amount of debris reaching the culvert was generally less for lower, or higher simulated ARI flow conditions. Interestingly, the percentage of debris reaching the culvert during the 50 year ARI flow was similar to that observed during the 2 year ARI flow. It was observed that the debris gained mobility with increasing depth and width of the channel.

Between the 20 year and the 50 year simulated ARI flows, the behaviour of the channel flow changed significantly. The main flow remained in the channel up to the 20 year ARI. However, as the flow approached the 50 year ARI flowrate, the flow tended to overtop the sides of the channel and spread out over a greater area (Fig. 2). This resulted in a variety of new, shallower flow paths being established. A significant amount of the debris was found to become trapped in these newly flooded areas due to the shallower water depths, despite having no vegetation.

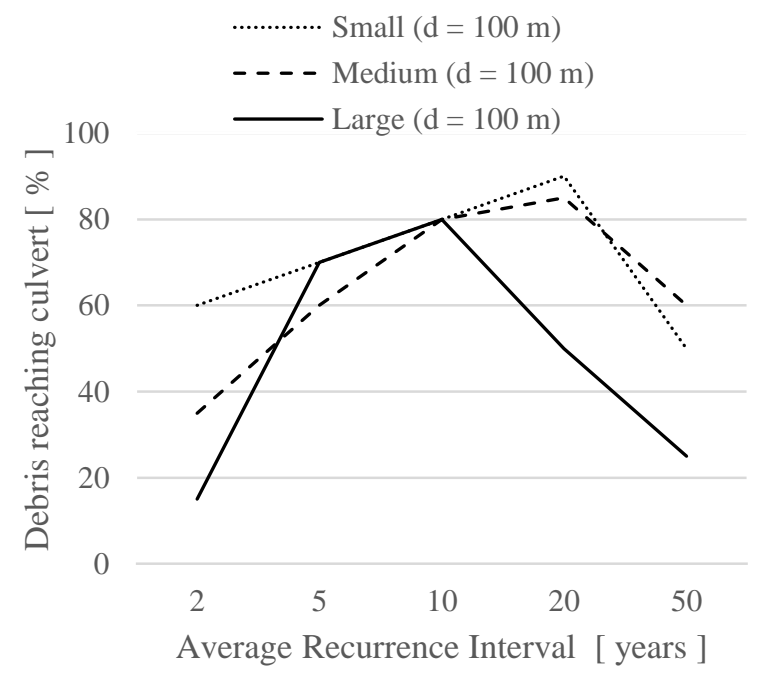

Figure 5: Percentage of debris reaching the culvert when dropped in at location $\mathrm{D}_{1}(100 \mathrm{~m})$

When the debris was dropped into the stream at location $\mathrm{D}_{2}(50 \mathrm{~m}$ from the culvert), the results demonstrate very different mobility behaviour (Figure 6). Initially, the amount of debris reaching the culvert reduced as the channel flowrate increased. The minimum amount reaching the culvert was observed to occur between the simulated 10 year and 20 year ARI flows for all three debris types. At 
flows of 20 years and above, the amount of debris reaching the culvert started increasing again (Figure $6)$.

It was observed that the simulated vegetation next to the streambed became more submerged as the water levels increased with the higher ARI flowrates. This resulted in more debris becoming stuck within the riparian vegetation zones while trying to establish a stable position within the flow. The minimum amount of debris reached the culvert during the simulated 10 year ARI flow event for the small and medium sized debris. However, the minimum amount of large debris was observed during the 20 year ARI event. With higher flowrates during the 20 and 50 year ARI the flow velocities increased, which lead to higher dragging forces that tended to move the debris further downstream.

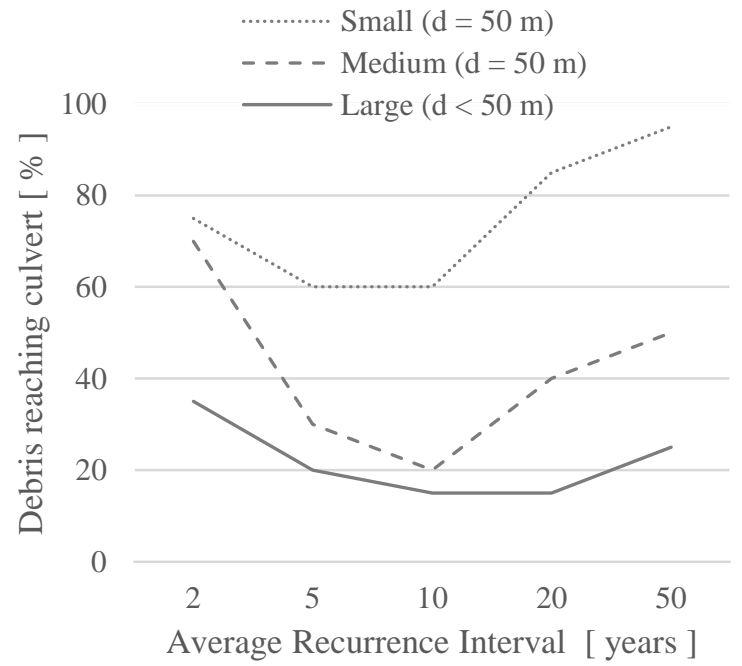

Figure 6: Percentage of debris reaching the culvert when dropped in at location $\mathrm{D}_{2}(50 \mathrm{~m})$

\section{DISCUSSION}

During the drop-in location $\mathrm{D}_{1}$ experiments, it was found that most of the debris would try to align itself with the stream flow and then travel downstream to reach the culvert. As there was no vegetation next to the stream between locations $D_{1}$ and $D_{2}$, the debris had more time to align itself with the flow in the stream without being hindered by riparian vegetation. It was observed that once the debris found a stable position within the flow, it tended to maintain this position and travel all the way to the culvert entrance.

However, for the 2 year and 50 year ARI flowrates, a higher amount of the debris became lodged in the channel due to lower water depth and smaller channel width. During the 50 year ARI flow, the water levels were relatively high and some debris left the former streambed which led to debris being trapped in these flooded area due to low water depths.

The results of the experiments using drop-in location $\mathrm{D}_{2}$ with simulated vegetation along the channel sides were very different. At flows above the 2 year ARI, when the debris started to flow in between the simulated channel vegetation at location $\mathrm{D}_{2}$, a high proportion of the debris became trapped within the vegetation. It was observed that the minimum amount of debris was trapped during the simulated 10 year and 20 year ARI flows (Figure 6).

With further increasing flowrates, a higher percentage of debris reached the culvert. This appeared to be due to higher flow velocities, and therefore higher drag forces being exerted on the debris. The flooded terrain had no significant influence on the debris when it was released closer to the culvert at location $\mathrm{D}_{2}$. The most direct route to the culvert was still within the existing channel and this led to most debris remaining in the channel and reaching the culvert.

In order to visualise the general differences between debris dropped in to the flow at locations $D_{1}$ and $D_{2}$, the average of the two sets of results were calculated. These results are shown on Figure 7.

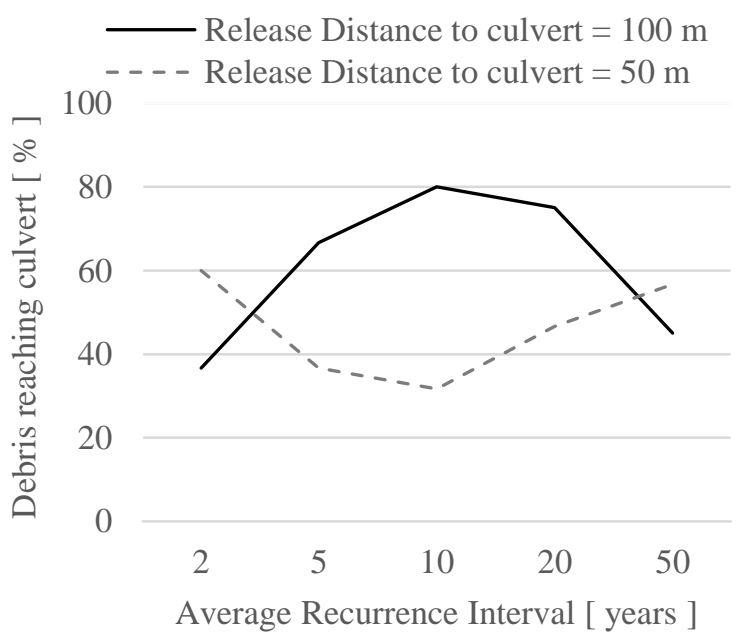

Figure 7: Average amount of debris reaching the culvert from both locations $(50 \mathrm{~m}$ and $100 \mathrm{~m})$

Figure 7 shows that the maximum amount of debris reached the culvert during the 10 year ARI flowrate in non-vegetated channels. Conversely, Figure 7 shows that the 10 year ARI flowrate also resulted in the minimum amount of debris reaching the culvert in vegetated channels. 
These results suggest that the potential for culvert blockage could be highly dependent on the condition of the riparian vegetation in the catchment. This could have significant implications for culvert design and maintenance procedures. However, further research would be required to investigate this in more detail.

\section{CONCLUSION}

This study investigated debris mobility in natural channels during high intensity rainfall events. Due to the extremely variable characteristics of natural (and simulated) rainfall events [25], and the associated risk of flooding, results observed during testing of the culvert rig were also found to be highly variable. Although the study was undertaken on a 1:25 scaled laboratory model, scaling effects on a model of this size are considered to be acceptable. The study findings have resulted in a better understanding of the factors that affect debris transportability and mobility in natural streams and channels. The main findings of the study were:

- Smaller debris is more likely to move downstream - the ratio between debris length and shape to channel width was found to be an important predictor of debris mobility.

- Low water depth can hinder debris mobility - greater water depth and a greater channel width promote debris transportability.

- Obstacles within the stream increase the likelihood of debris becoming trapped.

- Higher flow velocities were generally found to reduce debris trapping within the main channel due to increased drag forces.

The variable nature of the results of this study suggest that further research is required to develop an accurate model to predict debris transport. The experiments showed that the debris transportability is not only highly dependent on the flowrate and the size of the debris, but also on the point of entrance into the stream and on any obstacles along the stream bed.

The results of this study may have implications for culvert cleaning and maintenance schedules. They also suggest that it may be important for designers to take the amount and size of existing, and future, upstream catchment vegetation, as well as the local site environmental conditions into account during the culvert design stage.

The study results suggest that the increased stream depth and width (and the rate of this change) that occur during rainfall events, as well as the size and availability of debris, may be the main drivers that influence culvert blockage and potential flooding. However, more research is needed to verify this.

\section{REFERENCES}

[1] T. Lucke and S. Beecham, "Field investigation of clogging in a permeable pavement system," Building Research and Information, vol. 39, no. 6, pp. 603-615, 2011.

[2] M. E. Dietz, "Low impact development practices: A review of current research and recommendations for future directions," Water, Air, and Soil Pollution, vol. 186, no. 1-4, pp. 351-363, 2007.

[3] P. W. Nichols, R. White, and T. Lucke, "Do sediment type and test durations affect results of laboratory-based, accelerated testing studies of permeable pavement clogging?" Science of The Total Environment, vol. 511, pp. 786-791, 2015.

[4] E. J. Plate, "Flood risk and flood management," Journal of Hydrology, vol. 267 , no. $1-2$, pp. 2-11, 2002.

[5] J. Blanc, N. P. Wallerstein, G. B. Wright, and S. Arthur, "Analysis of the performance of debris screens at culverts," Proceedings of the Institution of Civil Engineers: Water Management, vol. 167, no. 4, pp. 219-229, 2014.

[6] W. Weeks, G. Witheridge, E. Rigby, A. Barthelmess, and G. O'Loughlin, “Australien Rainfall \& Runoff - Project 11: Blockage of Hydraulic Structures: Stage 1 Report," Engineers Australia, Barton ACT 2600, Australia, 2009. Accessed on: May 102016.

[7] W. Weeks, G. Witheridge, E. Rigby, A. Barthelmess, and G. O'Loughlin, "Australien Rainfall \& Runoff - Project 11: Blockage of Hydraulic Structures: Stage 2 Report," Engineers Australia, Barton ACT 2600, Australia, Feb. 2013. Accessed on: Apr. 07 2016.

[8] C. A. Braudrick and G. E. Grant, "When do logs move in rivers?," (en), Water Resources Research, vol. 36, no. 2, pp. 571-583, http://onlinelibrary.wiley.com/doi/10.1029/19 99WR900290/pdf, 2000.

[9] N. P. Wallerstein, C. V. Alonso, S. J. Bennett, and C. R. Thorne, "Distorted Froude-scaled flume analysis of large woody debris," (en), 
Earth Surface Processes and Landforms, vol. 26, no. 12, pp. 1265-1283, 2001.

[10] D. Bocchiola, M. C. Rulli, and R. Rosso, "Transport of large woody debris in the presence of obstacles," Geomorphology, vol. 76, no. 1-2, pp. 166-178, 2006.

[11] H. Chanson, The Hydraulics of Open Channel Flow: An Introduction; Basic Principles, Sediment Motion, Hydraulic Modelling, Design of Hydraulic Structures. Amsterdam: Butterworth-Heinemann, 2004.

[12] H. Chanson, "Turbulent air-water flows in hydraulic structures: Dynamic similarity and scale effects," Environ Fluid Mech, vol. 9, no. 2, pp. 125-142, 2009.

[13] J. B. Bradley, D. L. Richards, and C. C. Bahner, Debris control structures: Evaluation and countermeasures, 3rd ed. [Washington, D.C.]: U.S. Dept. of Transportation, Federal Highway Administration, 2005.

[14] A. M. Gurnell, H. Piegay, F. J. Swanson, and S. V. Gregory, "Large wood and fluvial processes," Freshwater Biol, vol. 47, no. 4, pp. 601-619, 2002.

[15] C. J. Gippel, B. L. Finlayson, and I. C. O'Neill, "Distribution and hydraulic significance of large woody debris in a lowland Australian river," (en), Hydrobiologia, vol. 318, no. 3, pp. 179-194, http://link.springer.com/content/pdf/10.1007 \%2FBF00016679.pdf, 1996.

[16] A. A. Webb and W. D. Erskine, "Distribution, recruitment, and geomorphic significance of large woody debris in an alluvial forest stream: Tonghi Creek, southeastern Australia," Interactions between Wood and Channel Forms and Processes, vol. 51, no. 1-3, pp. 109-126, 2003.

[17] J. C. Curran, "Mobility of large woody debris (LWD) jams in a low gradient channel," Geomorphology, vol. 116, no. 3-4, pp. 320329, 2010.

[18] J. van Sickle and S. V. Gregory, "Modeling inputs of large woody debris to streams from falling trees," Can. J. For. Res, vol. 20, no. 10, pp. 1593-1601, 1990.

[19] C. A. Braudrick and G. E. Grant, "Transport and deposition of large woody debris in streams: A flume experiment," Geomorphology, vol. 41, no. 4, pp. 263-283, 2001.
[20] D. Bocchiola, M. C. Rulli, and R. Rosso, "A flume experiment on the formation of wood jams in rivers," Water Resources Research, vol. 44, no. 2, 2008.

[21] J. Paik and S.D. Park, Numerical simulation of flood and debris flows through drainage culvert, Italian J. Eng. Geol. Environ. vol. 11, pp. 487-493

[22] D. H. Pilgrim and R. P. Canterford, Australian rainfall and runoff: A guide to flood estimation, 3rd ed, 1987.

[23] M. J. Boyd, E. H. Rigby, and R. VanDrie, "WBNM - a computer software package for flood hydrograph studies," Environmental Software, vol. 11, no. 1-3, pp. 167-172, 1996.

[24] F. M. Henderson, Open channel flow. Upper Saddle River, NJ: Prentice Hall, 1966.

[25] D. A. Lyn, T. Cooper, Y.-K. Yi, R. Sinha, and A. R. Rao, "Debris Accumulation at Bridge Crossings: Laboratory and Field Studies," FHWA, Purdue University, Oct. 2003.

Copyright (C) Int. J. of GEOMATE. All rights reserved, including the making of copies unless permission is obtained from the copyright proprietors. 